\title{
Existence of Myodural Bridge in the Trachemys scripta elegans: Indication of its Important Physiological Function
}

\author{
Existencia del Puente Miodural en Trachemys scripta elegans: \\ Indicación de su Importante Función Fisiológica
}

\author{
Zhao Huangfu'; Xiao Zhang'; Jia-Ying Sui ${ }^{1}$; Qi-Qi Zhao ${ }^{1}$; Xiao-Ying Yuan ${ }^{3}$; Chan Li³; Ya-Ru Dou ${ }^{3}$; \\ Wei Tang ${ }^{3}$; Mei-Ling Du ${ }^{3}$; Nan Zheng ${ }^{3}$; Yan-Yan $\mathrm{Chi}^{3}$; Sheng-Bo Yu ${ }^{3}$ \& Hong-Jin $\mathrm{Sui}^{3}$
}

HUANGFU, Z.; ZHANG, X.; SUI, J. Y.; ZHAO, Q. Q.; YUAN, X. Y.; LI, C; DOU, Y. R.; TANG, W.; DU, M. L.; ZHENG, N.; CHI, Y. Y.; YU, S. B. \& SUI, H. J. Existence of myodural bridge in the Trachemys scripta elegans: Indication of its important physiological function. Int. J. Morphol., 37(4):1353-1360, 2019.

SUMMARY: The myodural bridge (MDB) is confirmed that connecting the most of suboccipital muscles to the cervical dura mater through the posterior intervertebral spaces and widely exists in mammals and birds. In order to reveal whether the MDB is universally existing in amniota of vertebrates, we explored the existence and the morphological features of the MDB in the Trachemys scripta elegans. Twenty fresh red-eared slider specimens were observed by the gross anatomy dissection and histological analysis. In the results, three kind of muscles in the postoccipital region of the red-eared slider were found. The rectus capitis dorsum minor muscle originated from the posterior margin of the occiput $(\mathrm{C} 0)$ and terminated at the spinous process of the atlas $(\mathrm{C} 1)$. The transversospinales muscle was attached to the vertebral arch and the postzygapophysis of the atlas and extended to the spinous process of the axis (C2). The C2-C3 intertransversales muscle were extended from the postzygapophysis of $\mathrm{C} 2$ and the one of $\mathrm{C} 3$. The three muscles covered the dorsal interspaces among $\mathrm{C} 0-\mathrm{C} 3$, and meantime they were closely connected with dense connective tissues, which filled in these interspaces. Each of these thick dense connective tissue membranes sent off several short and strong fibrous bundles ventrally to merge with the cervical spinal dura mater. Furthermore the connective tissues connecting these muscles with cervical spinal dura mater directly were revealed under the microscopy and they consisted of parallel and intensive collagen fibers with orientation from dorsal to ventral. In conclusion, this study for the first time demonstrated the existence of the MDB in the testudines, in all of the dorsal atlantooccipital, atlantoaxial and C2-C3 intervertebral spaces. Based on our results and comparative anatomical evidences in recent year, it could be inferred that the MDB might be its highly conserved structure in the evolution of amniota.

KEY WORDS: Myodural bridge; Trachemys scripta elegans; Amniota; Evolutionary conservation.

\section{INTRODUCTION}

The myodural bridge (MDB) was a kind of dense connective tissue extending from the ventral surface of most of the suboccipital muscles to the dorsal surface of the cervical spinal dura mater (Enix et al., 2014). In human, the suboccipital muscles include the rectus capitis posterior minor (RCPmi), rectus capitis posterior major (RCPma), oblique capitis inferior (OCI) and oblique capitis superior. Among them, the RCPmi gave off dense fibers to take part into the posterior atlantooccipital membrane and partly transmitted the latter to enter the epidural space and then fused with the cervical spinal dura mater (Kahn et al., 1992; Hack et al., 1995; Mitchell et al., 1998; Humphreys et al., 2003; Nash et al., 2005; Sui et al., 2013; Zheng et al., 2014; Yuan et al., 2016). The RCPma and OCI are located dorsal and inferior to the RCPmi and together to cover the posterior atlanto-axial interspace. They also sent off dense fibers passing through this interspace to enter the epidural space and then connected with the cervical spinal dura mater (Scali et al., 2011, Pontell et al., 2013a,b; Scali et al., 2013a,b).

In view of the structural features of the MDB, it was assumed that the MDB may play a role in preventing the enfolding of the cervical dura mater, maintaining the

\footnotetext{
${ }^{1}$ The Second Affiliated Hospital of Dalian Medical University, Dalian, Liaoning 116021, China.

2 The First Affiliated Hospital of Dalian Medical University, Dalian, Liaoning 116000, China.

${ }^{3}$ Department of Anatomy, College of Basic Medicine, Dalian Medical University, Dalian, Liaoning 116044, China.

Grant sponsor: This work was supported by Natural Science Foundation of China (NSFC31600972, NSFC31571234), Liaoning Province Department of Education Funds (L2016012, L2015156).
} 
HUANGFU, Z.; ZHANG, X.; SUI, J. Y.; ZHAO, Q. Q.; YUAN, X. Y.; LI, C; DOU, Y. R.; TANG, W.; DU, M. L.; ZHENG, N.; CHI, Y. Y.; YU, S. B. \& SUI, H. J. Existence of myodural bridge in the Trachemys scripta elegans: Indication of its important physiological function. Int. J. Morphol., 37(4):1353-1360, 2019.

subarachnoid space or transmitting the tense of dura mater (Hack et al.; Alix \& Bates, 1999; Nash et al.; Tagil et al., 2005; Scali et al., 2011; Pontell et al., 2013b; Scali et al., 2013 b). Moreover, the MDB was supposed to be an important power resource of the cerebrospinal fluid (CSF) circulation, which acted as a pump (Sui et al.; Zheng et al., 2014; Yuan et al.; Scali et al., 2011). So far its role in human has been debated. In order to reveal its physiological function, recently a lot of comparative anatomy studies were implemented and their results showed that the MDB universally existed in mammals and birds (Liu et al., 2017; Zheng et al., 2017). It was indicated that the MDB might be a high conservative anatomical structure with a indispensable function in vertebrate evolution.

Furthermore, it is generally believed that reptiles are the basis of evolution of mammals and birds and all are amniota. Whether does the MDB universally exit in amniota? Recently Zhang et al. (2016), found that the Siamese crocodile has columnar MDB-like structure in its suboccipital region. It was shown that the MDB might appear in crocodilia. A red-eared slider is a subspecies of the Trachemys scripta, belonging to the Cryptodira of Chelonia. Unlike crocodilia, the neck and the head of the red-eared slider could be retracted in the vertical plane to the position between the shoulder girdles (Herrel et al., 2007; Jones et al., 2012; Werneburg et al., 2015a,b). In order to enrich the evidence of the MDB existing in reptiles, the structure and morphology of head and neck of the red-eared slider were study in this research.

Ethics Statement. Twenty red-eared sliders were purchased from seafood market in Dalian with the permission of Chinese Authorities for Animal Protection. All red-eared sliders were executed by intraperitoneal injecting with excess $4 \%$ Chloral hydrate solution. These red-eared sliders were permitted for scientific research under the approval of the Ethics Committee of Dalian Medical University.

\section{MATERIAL AND METHOD}

Dissection of the postoccipital region. Ten fresh head and neck specimens were dissected layer-by-layer at posterior occipital region to explore deep postoccipital muscles along the vertebrae $\mathrm{C} 1-\mathrm{C} 3$. These muscles was separated from their cranial insertions respectively and to show connections between them and the dorsal intervertebral membrane. Then the membranes was incised along its cranial end to open the dorsal intervertebral space and then observe connections between this membrane and the cervical spinal dura mater. Image results of gross anatomy dissection were taken with Canon 7D and Olympus CCD.

Histology analysis. Ten fresh head and neck specimens were fixed in $10 \%$ formalin and then decalcified in $8 \%$ hydrochloric acid for 14-18 days. Neck and head tissue blocks were prepared including tissues from occipital part of head to the third cervical vertebra levels. After regular paraffin embedding, serial 14-mm section, and VG and Masson staining, fibrous connections between the muscular structure and cervical spinal dura mater were observed under the light microscope. The results of VG and Masson staining sections were photographed and analyzed by Nikon NIS image system (Nikon Eclipse 80i).

\section{RESULTS}

Anatomy dissection. Ten fresh specimens were dissected and observed. It was found that the cranium and seven cervical vertebrae and cranial bones of the red-eared slider were jointed together in "L" shape, and the head could be retracted via the dorsiflexion of cervical vertebral joints. Along the dorsal aspect of first three cervical vertebrae, three muscles were identified. The rectus capitis dorsum minor (RCDmi) (Fig. 1a), the transversospinales (Fig. 1b) and the $\mathrm{C} 2-\mathrm{C} 3$ intertransversales muscles (Fig. 1c). The RCDmi was originated from the posterior margin of the occipital bone and terminated in the spinous process of the atlas (Fig. 1a). And at the ventral side of RCDmi, it was tightly connected with the dorsal atlanto-occipital membrane (DAOM), which filled in the dorsal atlanto-occipital interspace. And then several trabecula-like structures were originated from the ventral side of DAOM, through the epidural space and attached to the cervical spinal dura mater (Fig. 1A). In the atlas (C1) and axis (C2) segments, the transversospinales muscle was found. It was attached to the vertebral arch and the postzygapophysis of the atlas cranially and inserted at the spinous processe of the axis caudally (Fig. 1b). Its ventral side covered the dorsal atlantoaxis interspace, and meanwhile it connected densely with the dorsal atlantoaxis membrane (DAAM), which filling in this interspace, and then towards the epidural space the DAAM gave off lots of dense connective bands ventrally to merge into the cervical spinal dura mater finally (Fig. 1B).

In the axis and C3 segments, the intertransversales muscle was found to be located between the postzygapophysis of the axis and the $\mathrm{C} 3$ covering the dorsal intervertebral space (Fig. 1c). Its ventral side were tightly linked with the dorsal intervertebral membrane (DIVM). 

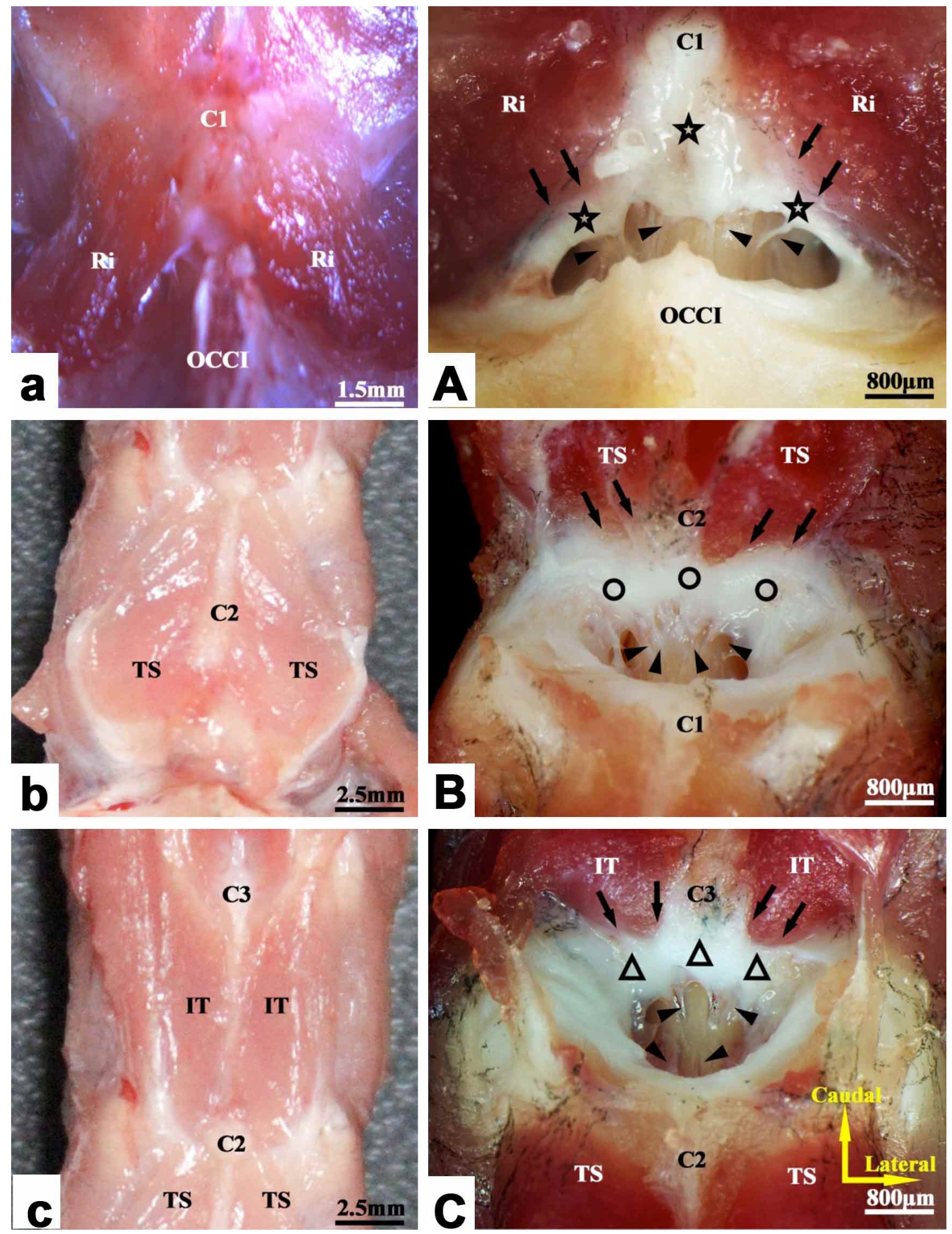

Fig. 1. The continuous structure from the postoccipital muscles to the cervical spinal dura mater based on the gross anatomy dissection. OCCI: the occipital bone. DM: dura mater. RCDmi: the rectus capitis dorsum minor muscle. TS: the transversospinales. IT: the C2-C3 intertransversales muscle. Star: the dorsal atlantooccipital membrane. Ring: the dorsal atlantoaxial membrane. Hollow Triangle: the C2-C3 dorsal intervertebral membrane. Filled Triangle : trabecular fibrous bundles. a/b/c: the overall view of the three muscles. A/B/C: The continuous structure from the postoccipital muscles to the cervical spinal dura mater. Arrow: connective tissue between muscles and trabecular fibrous bundles. 

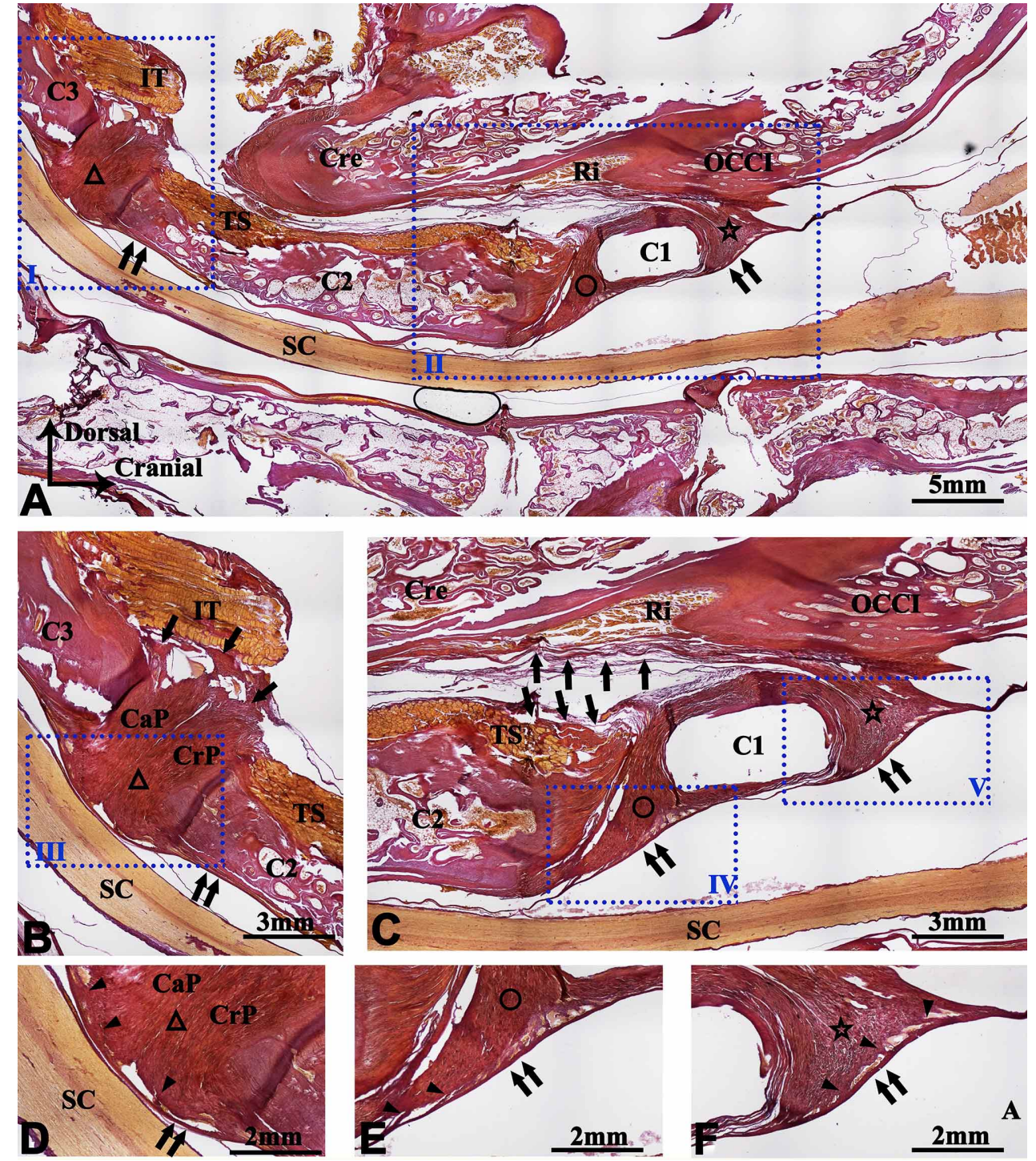

Fig. 2. The connection between the post-occipital muscles and the cervical dura mater based on the histological analysis (VG stain) on sagittal sections. OCCI: the occipital bone. Cre: the occipital crest. $\mathrm{Ri}$ : the rectus capitis dorsum minor (RCDmi). TS: the transversospinales. IT: the C2-C3 intertransversales. SC: the spinal cord. Star : the atlantooccipital membrane. Ring: the atlantoaxial membrane. Hollow Triangle : the C2-C3 intervertebral membrane. Double Arrows: cervical spinal dura mater. Filled triangle : trabecular fibrous bundles. Arrow: connective tissue between muscles and trabecular fibrous bundles. Cap: caudal part. CrP: cranial part. Figure b is the enlarge view of frame I; Figure $\mathrm{c}$ is the enlarged view of frame II; Figure $\mathrm{d}$ is the enlarge view of frame III; Figure e is the enlarge view of frame IV; Figure $\mathrm{f}$ is the enlarged view of frame $\mathrm{V}$.

Meanwhile, the DIVM sent off several trabecular structures into the epidural space and ventrally connected with the cervical spinal dura mater (Fig. 1C).

In situ, the DAOM, DAAM and DIVM were pulled up while the corresponding muscles were drawn passively, and the cervical spinal dura mater was lifted dorsally in the meantime.

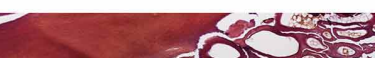

Histological staining. In the results of histological staining, the bony structures, the dura mater, and the spinal cord were identified clearly, and the RCDmi, the transversospinales, the $\mathrm{C} 2$ C3 intertransversales muscles were found according to their location, in the parasagittal sections of head and neck with the Van Gieson (VG) and the Masson stain (Figs. 2 and 3).

At the level of the dorsal atlantooccipital interspace, it was found that the DAOM was thick and composed of dense fibers, with parallel arrangement of the collagen tissue and most of them were originated from the ventral aspect of the RCDmi and ran cranially and ventrally to insert into the dorsal atlantooccipital interspace to participate in the formation of the DAOM. It this level, the epidural space was narrow and it was found that in this space the DAOM projected out several short and dense fibrous cords, to tightly connect with the cervical spinal dura mater.

And in the dorsal atlantoaxial interspace, the DAAM was showed to be composed of thick and dense fibers with parallel arrangement. Some of them were found to be originated from the transversospinales and ran cranially for a short distance until they made near 90 degree turn ventrally to join the DAAM. And then several short cord-like fibers were given off by the DAAM on its ventral aspect to insert into the cervical spinal dura mater.

And in the dorsal C2-C3 interspace, the DIVM was found to be composed of dense fibers with parallel arrangement, but it was thicker than the DAOM and DAAM 


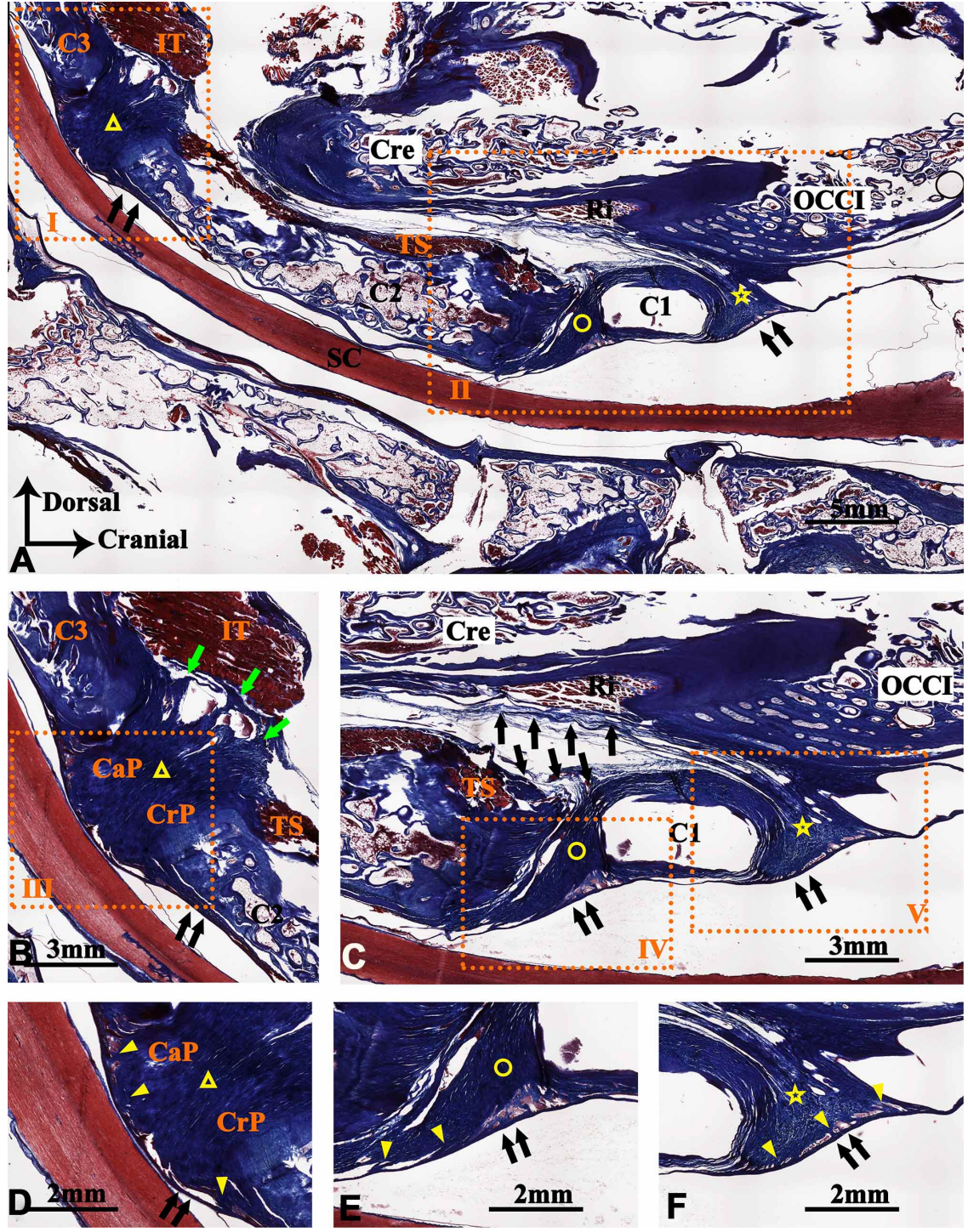

Fig. 3. The connection between the post-occipital muscles and the cervical dura mater based on the histological analysis (Masson stain) on sagittal sections. OCCI: the occipital bone. Cre: the occipital crest. Ri: the rectus capitis dorsum minor (RCDmi). TS: the transversospinales. IT: the C2-C3 intertransversales. SC: the spinal cord. Star : the atlantooccipital membrane. Ring : the atlantoaxial membrane. Hollow Triangle : the C2C3 intervertebral membrane. Double Arrows : cervical spinal dura mater. Filled Triangle : trabecular fibrous bundles. Arrow : connective tissue between muscles and trabecular fibrous bundles. Cap: caudal part. CrP: cranial part. Figure b is the enlarged view of frame I; Figure $\mathrm{c}$ is the enlarged view of frame II; Figure $\mathrm{d}$ is the enlarged view of frame III; Figure e is the enlarge view of frame IV; Figure $\mathrm{f}$ is the enlarged view of frame V. thick fibrous cords were projected by the caudal part to adhere to the cervical spinal dura mater tightly, however the cranial part of this membrane had few connections with the cervical spinal dura mater.

In addition, at level of the atlas (C1), the subarachnoid space was obviously larger than that of other vertebra levels (Figs. 2 and 3).

As a result of VG stain, muscular fibers were stained in yellow and collagen fibers were red (Fig. 2). Meanwhile, for the Masson stain, the muscular fibers were red and the collagen fibers were blue (Fig. 3). The two stain methods showed that the connective fibers between the deep postoccipital muscles and the cervical spinal dura mater consisted of collagenous fibers.

\section{DISCUSSION}

The myodural bridge (MDB) was a kind of dense connective tissue extending from the ventral surface of most of the suboccipital muscles to the dorsal surface of the cervical spinal dura mater. In human, the RCPmi, RCPma and OCI gave off the MDBs respectively and they were transmitted by the posterior intervertebtal membranes to enter the epidural space through the posterior atlantooccipital and atlantoaxis interspaces and then fused with the cervical spinal dura mater (Kahn et al.; Hack et al.; Mitchell et al.; Humphreys et al.; Nash et al.; Scali et al., 2011, Pontell et al., 2013a,b; Scali et al., 2013a,b; Sui et al.; Zheng et al., 2014; Yuan et al.).

and might be subdivided into cranial and caudal parts incompletely. On the dorsal aspect of DIVM, it was shown that the intertransversales muscle gave off lots of dense fibers to take part in this membrane and meanwhile the caudal end of transversospinales muscle also sent off dense fibers to take part in the cranial part of the DIVM. And then on the ventral aspect of the DIVM, a few of intensive, short and
Recently a lot of comparative anatomy studies showed that the MDB universally existed in mammals and birds (Liu et al.; Zheng et al., 2017).

In this study, it was found for the first time that the MDBs existed in the red-eared slider, these collagen fibers of MDBs entered the epidural space not only through the 
HUANGFU, Z.; ZHANG, X.; SUI, J. Y.; ZHAO, Q. Q.; YUAN, X. Y.; LI, C; DOU, Y. R.; TANG, W.; DU, M. L.; ZHENG, N.; CHI, Y. Y.; YU, S. B. \& SUI, H. J. Existence of myodural bridge in the Trachemys scripta elegans: Indication of its important physiological function. Int. J. Morphol., 37(4):1353-1360, 2019.

dorsal atlantooccipital and atlantoaxis interspaces but also through the dorsal C2-C3 interspace. At the level of the dorsal atlantooccipital interspace, the RCDmi gave off dense collagen fibrous bundles to insert into the DAOM, and then the DAOM sent trabecula-like dense fibrous bundles ventrally to attach to the cervical spinal dura mater. In the dorsal atlantoaxial interspace, the dense collagen fibers from transversospinales joined the DAAM. And then the DAAM projected out trabecula-like dense fibrous bundles to merge into the cervical spinal dura mater finally. As for the dorsal C2-C3 interspace, the DIVM was thick and made up of dense collagen fibers with parallel arrangement, which might be subdivided into cranial and caudal parts incompletely. The dense collagen fibers from the $\mathrm{C} 2-\mathrm{C} 3$ intertransversales muscle took part in the DIVM and meanwhile the dense collagen fibers from the transversospinales muscle mainly inserted into the cranial part. The short and dense trabeculalike collagen fiber cords mainly originated from the caudal part and then intensively attached to the cervical spinal dura mater. So the C2-C3 intertransversales muscle dominantly took part in the MDB system in the dorsal C2-C3 interspace. In summary, the RCDmi, transversospinales and C2-C3 intertransversales muscles sent out the MDBs through the corresponding intervertebral space and finally connected with the cervical dura mater.

As another kind of reptiles, the existing of MDB in Siamese Crocodile was proved. It connected the postoccipital muscles to the cervical spinal dura mater via the proatlas and DAOM, and that study found that in the epidural space the several thick trabeculae, as a terminal part of the MDB, were give off from the ventral aspect of the DAOM and atlas, and then inserted into the dura mater vertically (Zhang et al.). As the same as the siamese crocodile, although without the proatlas, the thick cord-like MDB's connection between the dorsal intervertebral membranes and the dural mater still emerged in the epidural space in the red-eared slider, and they were all composed of dense collagen fibers. It might be a general feature of the MDB in reptiles.

In human, dense collagen fibers of the MDB were mainly given off from the ventral aspect of the RCPmi, RCPma and OCI muscles and ran through the loose posterior atlantooccipital membrane (PAOM) to finally merge with the cervical spinal dura mater in particular area or through the loose posterior atlantoaxial membrane (PAAM) via the vertebral dural ligament (VDL) to finally merge with the cervical spinal dura mater in particular area (Hack et al.; Humphreys et al.: Mitchell et al.; Nash et al.; Sui et al.; Zheng et al., 2014; Yuan et al.; Zheng et al., 2018). Compared to Human Being, the DAOM and DAAM in Red-Eared Slider were constructed from thicker and denser collagen fibers with parallel arrangement, there was nota- ble difference between them. But the lots of dense collagen fibers from the deep post-occipital muscles were inserted into and built the DAOM and DAAM in Red-Eared Slider. It was similar to that of human. Furthermore, the most obvious differences between them were connection location and type between the dorsal intervertebral membrane (including the DAOM, DAAM, PAOM and PAAM) and the dura mater. In Red-Eared Slider the ventral aspect of dorsal intervertebvral membranes projected out dense collagen cord to connect with the cervical spinal dura mater in the epidural space. However, in human the dense collagen fibers of the MDB were mainly given off from the ventral aspect of the suboccipital muscles and ran through the loose posterior intervertebvral membranes to directly fuse with the cervical spinal dura (Zheng et al., 2014; Yuan et al.; Zheng et al., 2018). Besides, in RedEared Slider a dorsal intervertebral space was also present between the $\mathrm{C} 2$ and $\mathrm{C} 3$, and in this study, the MDB were found existing at the level of the dorsal C2-C3 interspace in Red-Eared Slider, but not in human being.

It has been confirmed that the MDB is a universal structure in mammals (Zheng et al., 2017) and birds (Liu et al.; Zheng et al., 2017). Furthermore, the MDB exists in the reptiles, based on our results together with the findings in the Siamese Crocodile (Zhang et al.). According to the above evidence, it could be inferred that the MDB might be highly conservative in cervical spine evolution of vertebrates, and it might be a universal structure in amniota. It was indicated that the MDB could have important physiological roles in vivo although the MDB had structural distinction between different species.

The red-eared slider is a subspecies of Trachemys scripta, which belongs to the Cryptodira of the Testudoformes. During feeding and escaping activity, the rapid movement is performed on neck (Herrel et al.). It is unique that the red-eared slider could retract the neck in the vertical plane between the shoulder girdles with high speed (Herrel et al.; Jones et al.; Werneburg et al., 2015a,b). So it was suggested that the MDBs existing would synchronize the dura mater with rapid motion of the cervical spine and in the meantime the large subarachnoid space was found dorsal to the cervical spine at the level of the atlas in our study and that meant the MDB might play important roles in a wide range.

In recent 20 years, many studies demonstrated that the MDB could play a part in preventing the dura mater from infolding in human (Alix \& Bates; Hack et al.; Nash et al.; Tagil et al.; Pontell et al., 2013b; Scali et al., 2011; Scali et al., 2013b). In the red-eared slider, the C2-C3 joint could perform wide range of dorsiflexion in feeding and escaping 
activity. In this period, the MDB through the dorsal C2-C3 interspace might play an important role in preventing infolding of the corresponding cervical spinal dura mater which might hurt the spinal cord when the C2-C3 joint dorsiflexion. It's possible that MDBs with a similar protective effect exit in the other joints caudal to the C3 in the redeared slider and it will be verified in future study. However, in atlantooccipital and the atlanoaxis joints, given that their dorsiflexion was obviously limited due to covered by the occipital crest and a large subarachnoid space appeared at this level, and so it was less possible that infolding of the corresponding cervical spinal dura mater happen to hurt the spinal cord. In summary, the MDB through the dorsal atlantooccipital and the atlanoaxis interspaces might mainly pull on the corresponding dura mater, and therefore creating negative pressure in a large wide subarachnoid space at the junction of head and neck to modulate the circulation of cerebrospinal fluid. Sui et al. and Zheng et al. (2014) suggested that the muscles-MDB-cervical spinal dura mater sleeve complex at the suboccipital region might have an important effect on the CSF circulation by acting as a pump. In this study, our finding offered the morphological support to the above-mentioned hypothesizes in evolution.

In conclusion, the MDB existed in the red-eared slider and it might be a universal structure in amniota. It was indicated that the MDB was highly conservative in cervical spine evolution of vertebrates with important physiological roles. Our study showed that the MDBs might play an important role in preventing infolding of the corresponding cervical spinal dura mater and therefore protecting the spinal cord during cervical spine motions and have an important effect on promoting the CSF circulation.

\section{ACKNOWLEDGEMENTS}

This work was supported by Natural Science Foundation of China (NSFC31600972, NSFC31571234), Liaoning Province Department of Education Funds (L2016012, L2015156).

HUANGFU, Z.; ZHANG, X.; SUI, J. Y.; ZHAO, Q. Q.; YUAN, X. Y.; LI, C; DOU, Y. R.; TANG, W.; DU, M. L.; ZHENG, N.; CHI, Y. Y.; YU, S. B. \& SUI, H. J. Existencia conservadora del puente miodural en Trachemys scripta elegans: Indicación de su importante función fisiológica. Int. J. Morphol., 37(4):1353-1360, 2019.

RESUMEN: Se confirma que el puente miodural (PMD) conecta la mayoría de los músculos suboccipitales con la duramadre cervical a través de los espacios intervertebrales posteriores y existe ampliamente en mamíferos y aves. Para revelar si el MDB existe universalmente en la amniota de vertebrados, exploramos la existencia y las características morfológicas del PMD en Trachemys scripta elegans. Veinte muestras se observaron mediante disección anatómica y análisis histológico. En los resultados, se encontraron tres tipos de músculos en la región occipital. El músculo recto capitis dorsum minor se originó en el margen posterior del occipital (C0) y terminó en el proceso espinoso del atlas (C1). El músculo transverso espinal se unió al arco vertebral y el proceso del atlas y se extendió al proceso espinoso del axis (C2). El músculo intertransversario $\mathrm{C} 2-\mathrm{C} 3$ se extendió entre los procesos transversos de $\mathrm{C} 2$ y el de $\mathrm{C} 3$. Los tres músculos cubrían los espacios intermedios dorsales entre $\mathrm{C} 0-\mathrm{C} 3 \mathrm{y}$, mientras tanto, estaban estrechamente conectados con tejidos conectivos densos, que rellenaban estos espacios. Cada una de estas membranas densas de tejido conectivo envían varios haces fibrosos cortos y fuertes ventralmente para fusionarse con la duramadre espinal cervical. Además, los tejidos conectivos que conectan estos músculos con la duramadre cervical y espinal se revelaron directamente bajo microscopía y consistían en intensas fibras de colágeno, paralelas, con orientación desde dorsal a ventral. En conclusión, este estudio demostró por primera vez la existencia del PMD en los estudios de prueba, en todos los espacios dorsales atlantooccipital, atlantoaxial e intervertebral C2-C3. Sobre la base de nuestros resultados y las evidencias anatómicas comparativas de los últimos años, se podría inferir que el PMD podría ser una estructura altamente conservada en la evolución de la amniota.

PALABRAS CLAVE: Puente miodural; Trachemys scripta elegans; Amniota; Conservación evolutiva.

\section{REFERENCES}

Alix, M. E. \& Bates, D. K. A proposed etiology of cervicogenic headache: the neurophysiologic basis and anatomic relationship between the dura mater and the rectus posterior capitis minor muscle. $J$. Manipulative Physiol. Ther, 22(8):534-9, 1999.

Enix, D. E.; Scali, F. \& Pontell, M. E. The cervical myodural bridge, a review of literature and clinical implications. J. Can. Chiropr. Assoc., 58(2):184-92, 2014.

Hack, G. D.; Koritzer, R. T.; Robinson, W. L.; Hallgren, R. C. \& Greenman, P. E. Anatomic relation between the rectus capitis posterior minor muscle and the dura mater. Spine (Phila Pa 1976), 20(23):2484-6, 1995.

Herrel, A.; Van Damme, J. V. \& Aerts, P. Cervical Anatomy and Function in Turtles. In: Wyneken, J.; Bels, V. L. \& Godfrey, M. H. (Eds.). The Biology of Turtles. Boca Raton, CRC Press, 2007. pp.145-67.

Humphreys, B. K.; Kenin, S.; Hubbard, B. B. \& Cramer, G. D. Investigation of connective tissue attachments to the cervical spinal dura mater. Clin. Anat., 16(2):152-9, 2003.

Jones, M. E.; Werneburg, I.; Curtis, N.; Penrose, R.; O'Higgins, P.; Fagan, M. J. \& Evans, S. E. The head and neck anatomy of sea turtles (Cryptodira: Chelonioidea) and skull shape in Testudines. PLoS One, 7(11):e47852, 2012.

Kahn, J. L.; Sick, H. \& Koritké, J. G. The posterior intervertebral spaces of the craniovertebral joint. Acta Anat. (Basel), 144(1):65-70, 1992.

Liu, P.; Li, C.; Zheng, N.; Xu, Q.; Yu, S. B. \& Sui, H. J. The myodural bridge existing in the Nephocaena phocaenoides. PLoS One, 12(3):e0173630, 2017. 
Mitchell, B. S.; Humphreys, B. K. \& O'Sullivan, E. Attachments of the ligamentum nuchae to cervical posterior spinal dura and the lateral part of the occipital bone. J. Manipulative Physiol. Ther., 21(3):145-8, 1998.

Nash, L.; Nicholson, H.; Lee, A. S.; Johnson, G. M. \& Zhang, M. Configuration of the connective tissue in the posterior atlanto-occipital interspace: a sheet plastination and confocal microscopy study. Spine (Phila Pa 1976), 30(12):1359-66, 2005.

Pontell, M. E.; Scali, F.; Enix, D. E.; Battaglia, P. J. \& Marshall, E. Histological examination of the human obliquus capitis inferior myodural bridge. Ann. Anat., 195(6):522-6, 2013a.

Pontell, M. E.; Scali, F.; Marshall, E. \& Enix, D. The obliquus capitis inferior myodural bridge. Clin. Anat., 26(4):450-4, 2013b.

Scali, F.; Marsili, E. S. \& Pontell, M. E. Anatomical connection between the rectus capitis posterior major and the dura mater. Spine (Phila Pa 1976), 36(25):E1612-4, 2011

Scali, F.; Pontell, M. E.; Enix, D. E. \& Marshall, E. Histological analysis of the rectus capitis posterior major's myodural bridge. Spine J., 13(5):558-63, 2013a.

Scali, F.; Pontell, M. E.; Welk, A. B.; Malmstrom, T. K.; Marshall, E. \& Kettner, N. W. Magnetic resonance imaging investigation of the atlantoaxial interspace. Clin. Anat., 26(4):444-9, 2013b.

Sui, H. J.; Yuan, X. Y.; Gao, H. B.; Xu, Q. \& Li, X. F. Anatomical study on the connections between the suboccipital structures and the spinal dura mater. Chinese J. Clin. Anat., 31:489-90, 2013.

Tagil, S. M.; Ozçakar, L. \& Bozkurt, M. C. Insight into understanding the anatomical and clinical aspects of supernumerary rectus capitis posterior muscles. Clin. Anat., 18(5):373-5, 2005.

Werneburg, I.; Hinz, J. K.; Gumpenberger, M.; Volpato, V.; Natchev, N. \& Joyce, W. G. Modeling neck mobility in fossil turtles. J. Exp. Zool. B Mol. Dev. Evol., 324(3):230-43, 2015a.

Werneburg, I.; Wilson, L. A.; Parr, W. C. \& Joyce, W. G. Evolution of neck vertebral shape and neck retraction at the transition to modern turtles: an integrated geometric morphometric approach. Syst. Biol., 64(2):187204, 2015b.

Yuan, X. Y.; Yu, S. B.; Li, Y. F.; Chi, Y. Y.; Zheng, N.; Gao, H. B.; Luan, B. Y.; Zhang, Z. X. \& Sui, H. J. Patterns of attachment of the myodural bridge by the rectus capitis posterior minor muscle. Anat. Sci. Int., 91(2):175-9, 2016.

Zhang, J. H.; Tang, W.; Zhang, Z. X.; Luan, B. Y.; Yu, S. B. \& Sui, H. J. Connection of the posterior occipital muscle and dura mater of the siamese crocodile. Anat. Rec. (Hoboken), 299(10):1402-8, 2016.

Zheng, N.; Chi, Y. Y.; Yang, X. H.; Wang, N. X.; Li, Y. L.; Ge, Y. Y.; Zhang, L. X.; Liu, T. Y.; Yuan, X. Y.; Yu, S. B.; et al. Orientation and property of fibers of the myodural bridge in humans. Spine J., 18(6):1081-7, 2018.

Zheng, N.; Yuan, X. Y.; Chi, Y. Y.; Liu, P.; Wang, B.; Sui, J. Y.; Han, S. H.; Yu, S. B. \& Sui, H. J. The universal existence of myodural bridge in mammals: an indication of a necessary function. Sci. Rep., 7(1):8248, 2017.

Zheng, N.; Yuan, X. Y.; Li, Y. F.; Chi, Y. Y.; Gao, H. B.; Zhao, X.; Yu, S. B.; Sui, H. J. \& Sharkey, J. Definition of the to be named ligament and vertebrodural ligament and their possible effects on the circulation of CSF. PLoS One, 9(8):e103451, 2014.

\author{
Corresponding author: \\ Prof.Sheng-Bo Yu \& Prof. Hong-Jin Sui \\ Department of Anatomy \\ College of Basic Medicine \\ Dalian Medical University \\ Dalian \\ CHINA
}

Email: ysbdmu@126.com
suihj@hotmail.com

Received: 13-04-2019

Accepted: 21-06-2019 